\title{
Construction and Operation of an Electronic Automatic Transfer Switch (Ats)
}

\author{
J.O. Olowoleni, A.U. Adoghe*, A. Ademola, A.O. Omadoye, A.F. Agbetuyi, \\ H.E. Orovwode and C.O. Awosope
}

Department of Electrical and Info Engineering, School of Engineering, Covenant University, Ota, Nigeria

\begin{abstract}
The inconsistency of power supply in Nigeria has been a major stumbling block to the advancement of her economy and as such it is an issue that requires immediate attention. Uninterrupted power supply is critical in so many applications especially in cases like hospital operations or financial transactions. This work was born out of the need to provide a cost effective and locally available way to automate the switching between various power sources. This issue can be addressed by implementing an Automatic transfer switch which automatically switches on a backup generator in the absence of the utility supply and transfers the load to the generator. The automatic transfer switch also switches off the backup generator and connects back to the utility supply when the power comes back. The circuitry consists of time delay integrated circuits and switching relays. The present effort is a prototype design to create an automatic transfer switch that can be used in an average Nigerian household because of its affordability and simplicity of operation.
\end{abstract}

Keywords: Generator, switching, relays, automatic-transfer, load transfer.

\section{INTRODUCTION}

A transfer switch is an electrical device that continuously monitors electric power utility and connects the load to a backup source of power if the utility power goes off [1]. This is designed to automatically switch the power supply to loads from a utility source to a backup source (such as a generator) and vice versa depending on the availability of the utility power source. The automatic transfer switch (ATS) also automatically switches OFF and ON the backup generator. The main components of this design are relays and a control unit based on a 4060B oscillator timer [2]. Basically, the way the automatic transfer switch works is that it senses the availability of the utility power supply and when the utility source is not available it switches $\mathrm{ON}$ the backup generator and transfers the load to the generator. This transfer of the load to generator is done after a predetermined time interval in order to allow for generator current to normalize [3].

The ATS also switches OFF the generator and reconnects the load back to the mains when the utility power is restored. This eliminates the stress and error of manually switching ON and OFF the generator [3].

\section{METHODOLOGY}

The automatic transfer switch's operation is based on a logical control unit which has a 4060B control

*Address correspondence to this author at the Department of Electrical and Info Engineering, School of Engineering, Covenant University, Ota; Tel: 08039404608; E-mail: anthony.adoghe@covenantuniversity.edu.ng oscillator as its main control component. This design consists of two distinct parts:

The power sensing unit, and Logic control unit.

Power sensing unit consists of the bridge rectifier circuit and Relay1 CRL1 as shown in Figure 1. The AC mains is connected to a step-down transformer, the output of this transformer is then rectified by a fullwave rectifier circuit. The bridge rectifier converts the AC output of the transformer to pulsating DC. The capacitor is used to filter out the DC and the zener diode is used to limit and stabilize the voltage to $12 \mathrm{~V}$. The diode $\mathrm{D} 4$ is used to protect RL1 from voltage spikes. When the utility power is $O N$ i.e. the $A C$ mains supply is ON, the rectifier circuit supplies 12VDC to RL1 and the normally open (NO) contact of the relay becomes normally closed (NC). The normally open contact of the relay is left unconnected while the normally closed contact of the relay is connected to Vcc of the control oscillator in the logic unit of the circuit. The common terminal of the relay is then connected to the positive terminal of the 12-V battery, while the negative terminal of the battery is connected to ground.

When electric power is available from the mains supply, it energizes relay3 CRL3 and terminals C3 and B3 of the relay are connected, when this happens there is no longer any supply to the $4060 \mathrm{~B}$ control oscillator. And this triggers a series of events in the control unit that leads to the load being connected to the mains power supply.

When there is no power being supplied from the utility source, RL3 is de-energized and terminals C3 
and $\mathrm{A} 3$ of the relay are connected together, when this happens the $12-\mathrm{V}$ battery supplies $12 \mathrm{~V}$ dc to the $4060 \mathrm{~B}$ control oscillator. This triggers a series of events in the control unit that leads to the automatic starting of the back-up generator and the connection of the load to the generator after a pre-set time [4]. The time delay is such that the generator can be fully stabilized before the load is connected to it.

\section{OPERATION OF THE LATCHES}

There are two latches used in this design and both of them are 4013B latches. The 4013B latch is originally designed for D-type applications but can be used as an SR latch by grounding both the $D$ input and the clock.

The two latches in the ATS are used to control the generator starter and also to control the changeover from one power source to another.

Latch1 has its output $Q$ connected to the base of transistor Q1 via a resistor. When the 4060B control oscillator is powered by the 12-v battery, its output pin 2 goes high after $0.62 \mathrm{sec}$, when this output goes high, it also makes the output $Q$ of latch1 go high and this in turn saturates the transistor Q1 which then energizes relay2. When relay2 is energized, it connects the motor/starter to ground thereby completing the circuit and starting the generator.

Latch2 has its output $Q$ connected to the base of transistor Q2 also via a resistor. When the 4060B control oscillator is powered by the $12-\mathrm{v}$ battery, its output pin 3 goes high after $1.234 \mathrm{secs}$. When this output goes high, it also makes the output $Q$ of latch2 go high and this, in turn, saturates the transistor Q2 which then energizes relay 1 . When relay 1 is energized it connects the load to the generator.

The ATS consists of 2 transistors (NPN) which are used to drive the relays. The application of a small current $I_{b}$ to the base of the transistor from the latch output $Q$ is used to control the transistor's larger collector current $\left(I_{c}\right)$. It is the collector current of the transistor that is now used to drive the relay.

When there is a base current applied to the transistor i.e. output from the latch is logical high, the transistor is driven to saturation region and it acts as a closed switch. This then energizes the relay. Likewise, when there is no base current applied to the transistor i.e. output from the latch is logical low, the transistor is driven to cut-off region and it acts as an open switch. This then de-energizes the relay.

The transistor is usually used with a resistor connected in series to it. This resistor helps to drive the transistor and it limits the amount of current that flows through the transistor thereby protecting the transistor from destruction because of overcurrent. The resistance of the resistor used in the control circuit of the ATS was calculated using equation 1 and $I_{\text {relay }}$ was found using equation 2 :

$R=\frac{\left(V_{b}-0.6\right) \times h f e}{I_{\text {relay }}}$

$\mathrm{I}_{\text {relay }}=\frac{V_{\text {relay }}}{R_{\text {relay }}}$

$V_{\text {relay }}=12 \mathrm{~V} ; R_{\text {relay }}$ given as $400 \Omega$,

therefore: $\mathrm{I}_{\text {relay }}=\frac{V_{\text {relay }}}{R_{\text {relay }}}=\frac{12}{400}=0.03 \mathrm{~A}$

where $V_{b}=$ Source voltage to the resistor $=5 \mathrm{~V}$

hfe $=$ Forward gain of the transistor $=150$ (gotten from the transistor datasheet); hence

$$
\begin{aligned}
& \mathrm{R}=\frac{(\mathrm{S}-0.6) \times 150}{0.03}=22 \mathrm{k} \Omega \\
& \mathrm{I}_{\text {resistor }}=\frac{\mathrm{V}}{\mathrm{R}}=5 / 22000=0.23 \mathrm{~mA} \\
& \beta=150 \\
& \mathrm{I}_{\mathrm{b}}=0.23 \mathrm{~mA} \\
& \beta=\frac{\mathrm{I}_{\mathrm{c}}}{\mathrm{I}_{\mathrm{c}}}, \mathrm{I}_{\mathrm{c}}=\beta \mathrm{I}_{\mathrm{b}}=0.0345=34.5 \mathrm{~mA} \\
& \mathrm{I}_{E}=\mathrm{I}_{\mathrm{b}}+\mathrm{I}_{\mathrm{C}}=0.03473=34.73 \mathrm{~mA}
\end{aligned}
$$

\section{LOGIC CONTROL UNIT}

The logic control unit is the "brain" of the automatic transfer switch [6]. It is the part of the circuit that controls the automatic switching of the generator and the transfer of load from the utility source to the backup generator when there is power outage. The logic control unit is achieved in the design of the ATS using the following components:

- $\quad$ 4060B control oscillator

- Two 4013B latches. 
- $\quad$ An inverting Schmitt trigger AND gate.

- $\quad$ Three resistors (10K, two 2k2).

- $\quad$ Two NPN transistors (25C945).

- $\quad$ Two 12V 5-pin relays.

- Two diodes.

\section{- Motor/starter}

How the logic control unit functions (a) when there is utility power supply and (b) when there is no utility power supply. This is described as follows:

\subsection{When There is Utility Power Supply}

When electric power is available from the mains supply, it energizes relay3 and terminals C3 and B3 of the relay are connected. When this happens, there is no longer supply to the $4060 \mathrm{~B}$ control oscillator. When there is no power supply to the control oscillator, its two outputs are low i.e. logical zero. A lack of power supply to the $4060 \mathrm{~B}$ control oscillator causes the following things to happen in the circuit:

- $\quad$ The output of latch1 is low and transistor1 (Q1) is at cut-off region. $Q_{1}$ acts like an open switch and relay2 is not energized therefore terminals $\mathrm{C}_{2}$ and $\mathrm{B}_{2}$ of the relay are connected together, and the generator starter is turned off.

- The output of latch2 is low and transistor2 $\left(\mathrm{Q}_{2}\right)$ is also at cut off region; $Q_{2}$ acts like an open switch and relay1 is not energized, therefore terminals $C_{1}$ and $B_{1}$ of the relay are connected together. This, in turn, connects the load to the mains supply.

- $\quad$ Also the input to the inverting Schmitt trigger is low. When this happens, the output of the Schmitt trigger is high thereby making the reset terminals of latches $1 \& 2$ high. This resets the latches and they remain that way until there is a high input to its set terminal and the reset terminal goes to low.

\subsection{When There is No Utility Power Supply}

When electric power is not available from the mains supply, relay3 de-energizes and terminals $\mathrm{C} 3$ and $\mathrm{A} 3$ of the relay are connected, the control oscillator is now powered by the $12-\mathrm{V}$ battery. Since the control oscillator is now powered by the $12-\mathrm{V}$ battery, its outputs are now high i.e. logical one.
The signal from pin 2 of the $4060 \mathrm{~B}$ is used to control the latch dealing with the automatic starting of the generator, while the signal from pin 3 of the $4060 \mathrm{~B}$ is used to control the latch that deals with the changeover control. There is a time delay between the starting of the generator and the loading of the generator; this is done to allow the generator attain stability before it is loaded. This time delay is achieved by pin3 going high only after pin2 has gone high. This time is calculated as follows:

$1 / \tau=\mathrm{F}_{\text {main }}=\frac{1}{2.3 \times \mathrm{R}_{\mathrm{t}} \times \mathrm{C}_{\mathrm{t}}}$

The typical values of $R_{2}, R_{t c}$ and $C_{t c}$ are respectively $100 \mathrm{~K} \Omega, 33 \mathrm{~K} \Omega$ and $0.001 \mu \mathrm{f}$.

$$
1 / \tau=\mathrm{F}_{\text {main }}=\frac{1}{2.3 \times\left(100 \times 10^{3}\right) \times\left(0.001 \times 10^{-6}\right)}=4.34 \mathrm{KHz}
$$

The values of $R_{t c}$ and $C_{t c}$ can be varied in order to obtain a desired frequency. For the case of this ATS, the output frequencies are then obtained using equation (4). Example of this calculation is as shown below:

$$
\begin{aligned}
& \mathrm{F}_{\mathrm{QX}}=\frac{\mathrm{F}_{\text {main }}}{2^{\mathrm{X}}} \\
& \mathrm{F}_{\mathrm{Q} 13}=\frac{F_{\text {main }}}{2^{1 \mathrm{~s}}} \text { e.t.c }
\end{aligned}
$$

- $\quad$ The frequency from pin2 (Q13)

$$
\begin{aligned}
& \mathrm{F}_{\mathrm{Q} 13}=\frac{F_{\text {main }}}{2^{13}}=\frac{13.2 K H_{Z}}{2^{13}}=1.61 \mathrm{KHz} \\
& \mathrm{T}_{\mathrm{Q} 13}=\frac{1}{F_{Q 13}}=\frac{1}{1.61}=0.62 \mathrm{sec}
\end{aligned}
$$

i.e. after $0.62 \mathrm{sec}$, pin2 goes high.

- $\quad$ The frequency from pin3 (Q14) is given as:

$\mathrm{F}_{\mathrm{Q} 14}=\frac{F_{\text {main }}}{2^{14}}=\frac{13.2 K H_{Z}}{2^{14}}=0.81 \mathrm{KHz}$

giving $\mathrm{T}_{\mathrm{Q} 14}=\frac{1}{F_{Q 14}}=\frac{1}{0.81}=1.234 \mathrm{secs}$

i.e. after 1.234 seconds, pin3 goes high.

A supply of power to the $4060 \mathrm{~B}$ control oscillator causes the following things to happen in the circuit: 
The output of latch1 is high and transistor1 $\left(Q_{1}\right)$ is at saturation region. $Q_{1}$ acts like a closed switch and relay2 is energized, therefore terminals $\mathrm{C}_{2}$ and $\mathrm{A}_{2}$ of the relay are connected together, and the generator starter is turned $\mathrm{ON}$.

$>\quad$ The output of latch2 is high and transistor2 $\left(Q_{2}\right)$ is also at saturation region. $Q_{2}$ acts like a closed switch and relay1 is energized therefore terminals $C_{1}$ and $A_{1}$ of the relay are connected together. This, in turn, connects the load to the generator.

Also the input to the inverting Schmitt trigger is high when this happens; the output of the Schmitt trigger is low thereby making the reset terminals of latches $1 \& 2$ low. This sets the latches and they remain that way until there is a low input to its set terminal and the reset terminal goes to high.

The signal from pin2 is used to control the latch that is responsible for automatically starting the generator. If the $12-\mathrm{V}$ battery is connected to the $4060 \mathrm{~B}$ (when there is no utility power supply), the generator is started after $0.62 \mathrm{sec}$. The signal from pin $3 \mathrm{on}$, the other hand is used to control the latch responsible for the change over of the load from mains to generator and vice versa. If the $12-\mathrm{V}$ battery is connected to the control oscillator, the change over occurs after 1.234 secs. The time delay helps stabilize the generator before it is loaded; hence it helps extend the useful life of both the generator and the load.

\section{PERFORMANCE EVALUATION OF THE ATS}

In order to simulate real life conditions under which the ATS can operate, two switches were added to the circuit. The switches are

A. Switch (1) is placed in series with the circuit immediately after the bridge rectifier

B. Switch (2) is placed in series between the $12 \mathrm{~V}$ battery and the common terminal of Relay 1.

These two switches will allow us simulate all the possible situations that can occur, these situations are as follows:

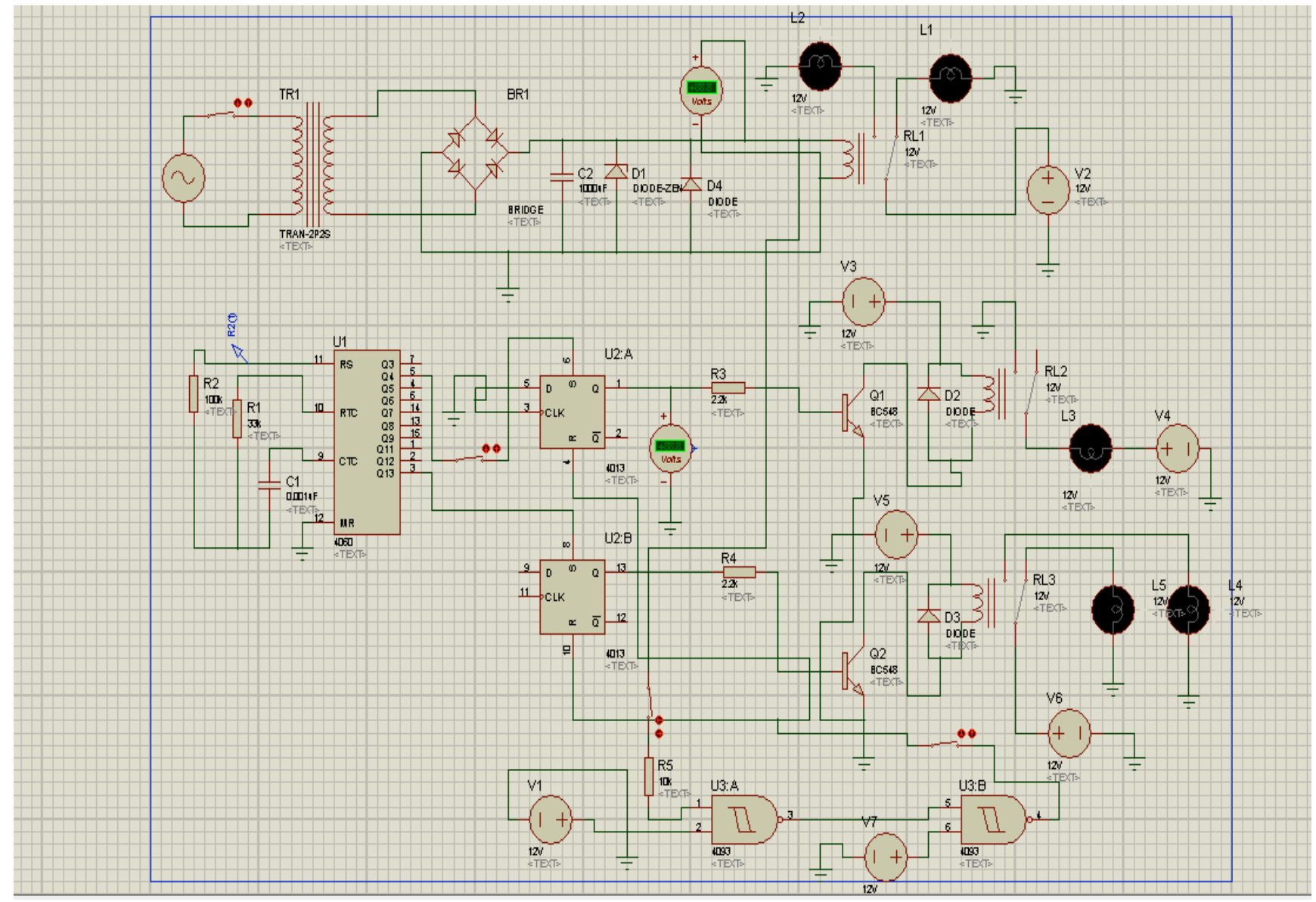

Figure 1: The system circuit diagram [7]. 
1. Absence of utility source and presence of Backup generator.

2. Absence of backup generator.

3. Presence of utility source and presence of backup generator.

4. Presence of utility source and absence of backup generator.

A 12-V motor was used to represent the generator starter mechanism because this is a prototype design. Also a 60-W lamp was used as the load and one phase of the utility supply was used as the generator in the absence of utility source and supply.

\section{CONCLUSION}

This project has been a very interesting and challenging one, but it has achieved its desired aims. The prototype of the ATS switch worked according to the design specification satisfactorily. The device is quite cheap, reliable and easy to operate. This will go a long way to improve power transition time, especially for low to middle class families which might not be able to afford industrial automatic transfer switches because of their exorbitant rates.

\section{REFERENCES}

[1] MS Ahmed, AS Mohammed, O.B Aguisiobo. Development of a single- phase Automatic Change over switch. Department of Electrical and Computer Engineering. Federal University of Technology Minna, Nigeria July 2006.

[2] Jonathan Gana Kolo. Design and construction of an automatic power changeover switch. Technical Report AU J T 2007; 11(2) Oct.

[3] LS Ezema, BU Peter, OO Harris. Design of an automatic changeover switch with generator control. Electrical Power and Electronic Development Department. Projects Develop Institute Enugu 2010.

[4] Thomas LF. Digital fundamentals integrated Circuits, $6^{\text {th }}$ ed Prentice-Hall Englewood Cliffs, NJ, USA (1997).

[5] Theraja BL. Theraja AK. A textbook of electrical technology 21 ed. Rajendra Ravindra Printers Ltd, S Chand \& Company Ltd Ram Nagar New Delhi India 2002.

[6] Microchip PIC 19F877 datasheet, retrieved online from www.microchip technology Inc January 2015.

[7] ATS-01 Ver1.0, Authomatic transfer switch control unit operator's manual: retrieved on December 2014.

Received on 31-12-2014

Accepted on 09-01-2015

Published on 01-04-2015

\section{DOl: http://dx.doi.org/10.15377/2409-5818.2014.02.01.1}

(C) 2014 Olowoleni et al.; Avanti Publishers.

This is an open access article licensed under the terms of the Creative Commons Attribution Non-Commercial License (http://creativecommons.org/licenses/by-nc/3.0/) which permits unrestricted, non-commercial use, distribution and reproduction in any medium, provided the work is properly cited. 